\title{
A redescoberta da ética do cuidado: o foco e a ênfase nas relações
}

\author{
THE REDISCOVERING OF THE ETHICS OF CARE: FOCUS AND EMPHASIS IN THE RELATIONSHIP \\ EL REDESCUBRIMIENTO DE LAÉTICA DEL CUIDADO: EL FOCO Y EL ÉNFASIS EN LAS RELACIONES
}

Elma Lourdes Campos Pavone Zoboli ${ }^{1}$

\section{RESUMO}

Este artigo tem por objetivo resgatar os sentidos, os aspectos históricos e as distintas estruturas explicativas da ética do cuidado, a fim de contribuir para o debate acerca do cuidar como bem interno e razão de ser da enfermagem. Também introduz o contraponto da ética de cunho feminino e da abordagem feminista da ética, explorando as possiveis motivações para o lugar periférico que tem cabido à ética do cuidado.

\section{PALAVRAS-CHAVE}

Bioética.

Ética.

Ética de enfermagem.

História.

\author{
ABSTRACT \\ The author presents $a$ \\ discussion of the meanings, the \\ historical aspects and the \\ different explanatory \\ frameworks for the ethics of \\ care. The main purpose is to \\ contribute to the debate \\ concerning the core role of \\ care in nursing and nursing \\ ethics. It also addresses the \\ opposition between feminine \\ and feminist ethics as an \\ explanation for the secondary \\ role of the ethics of care.
}

\section{KEYWORDS}

Bioethics.

Ethics.

Ethics, nursing.

History.

\section{RESUMEN}

Este trabajo objetiva rescatar los sentidos, los aspectos históricos y las distintas estructuras explicativas de la ética del cuidado, con miras a contribuir en el debate acerca del cuidar como el bien interno y la razón de ser de la enfermería. También plantea la contraposición de las éticas femeninas y las feministas, en la búsqueda de las posibles razones para el rol secundario de la ética del cuidado.

\section{PALABRAS CLAVE}

Bioetica.

Ética.

Ética de enfermería.

Historia.

\author{
1 Professora \\ Assistente do \\ Departamento de \\ Enfermagem em \\ Saúde Coletiva de \\ Escola de Enfermagem \\ da USP, Mestre em \\ Bioética, Mestre em \\ Saúde Pública, \\ Secretária da \\ Sociedade Brasileira \\ de Bioética e da \\ Sociedade de Bioética \\ de São Paulo. \\ Membro da diretoria \\ da Associação \\ Internacional de \\ Bioética. \\ elma@usp.br
}




\section{INTRODUÇÃO}

Ao longo dos tempos, a enfermagem tem compreendido e sustentado o cuidado como seu bem interno. Parece oportuno, então, propor no presente artigo um resgate dos diversos sentidos, da historicidade e das características da ética do cuidado, com vistas a contribuir para o debate que se trava acerca das especificidades do cuidar.

Após a edição do livro "Uma voz diferente: psicologia da diferença entre homens e mulheres da infância à idade adulta" de Carol Gilligan, em 1982, abordando a perspectiva do cuidado no desenvolvimento moral das mulheres, emerge uma ética do cuidado, questionando as concepções éticas vigentes com vistas a valorizar não apenas os atos, as motivações e o caráter dos envolvidos, mas se as relações positivas são ou não favorecidas ${ }^{(1)}$.

É comum, desde então, trabalhos contrastando a visão com base nos princípios ou direitos individuais, que fica conhecida como ética da justiça e a ética do cuidado:

\begin{tabular}{|c|c|}
\hline Ética do cuidado & Ética da justiça \\
\hline $\begin{array}{l}\text { Abordagem contextual } \\
\text { Conexão humana } \\
\text { Relacionamentos comunitários } \\
\text { Âmbito privado } \\
\text { Reforça o papel das emoções(sentimentos) } \\
\text { É relativa ao gênero feminino } \\
\text { (female/feminine/feminist) }\end{array}$ & $\begin{array}{l}\text { Abordagem abstrata } \\
\text { Separação humana } \\
\text { Direitos individuais } \\
\text { Âmbito público } \\
\text { Reforça o papel da razão } \\
\text { É relativa ao gênero masculino } \\
\text { (male/masculine/masculinist) }\end{array}$ \\
\hline
\end{tabular}

A noção de cuidado, entretanto, remonta a épocas anteriores, com obras literárias da Antiga Roma e fontes mitológicas e filosóficas que conformam suas raízes. Usualmente, a literatura sobre a ética do cuidado presta pouca atenção a esta história anterior à década de 80 , porém conhecer este horizonte mais amplo de significados pode iluminar e desafiar este emergente paradigma da ética e da bioética.

\section{ASPECTOS HISTÓRICOS}

A filologia da palavra 'cuidado' aponta sua derivação do latim cura (cura), que constitui um sinônimo erudito de cuidado. Na forma mais antiga do latim, a palavra cura escreve-se coera e é usada, num contexto de relações de amor e amizade, para expressar uma atitude de cuidado, de desvelo, de preocupação e de inquietação pela pessoa amada ou por um objeto de estimação. Estudos filológicos indicam outra origem para a palavra 'cuidado', derivando-a de cogitarecogitatus, que significa cogitar, pensar, colocar atenção, mostrar interesse, revelar uma atitude de desvelo e de preocupação. Como se pode notar, a natureza da palavra 'cuidado' inclui duas significações básicas, intimamente ligadas entre si: a primeira uma atitude de desvelo, de solicitude e de atenção para com o outro e a segunda uma preocupação e inquietação advindas do envolvimento e da ligação afetiva com o outro por parte da pessoa que cuida. Assim, parece que a filologia da palavra 'cuidado' indica que cuidar é mais que um ato singular; é modo de ser, a forma como a pessoa se estrutura e se realiza no mundo com os outros. É um modo de ser no mundo que funda as relações que se estabelecem com as coisas e as pessoas ${ }^{(1-2)}$.

Estas noções de cuidado como preocupação e solicitude e o entendimento de que o cuidar é essencial para o ser humano conforma elementos centrais na fábula-mito grecolatina, que ganha expressão literária definitiva na Roma do final da era pré-cristã. Mais do que qualquer outra fonte, esta alegoria encontrada em uma coletânea mitológica do segundo século da era cristã tem influenciado a idéia de cuidado na literatura, filosofia, psicologia e ética, através dos séculos.

Segundo a versão livre para o português do texto latino que é apresentada em Boff ${ }^{(2)}$, conta esta fábula-mito:

Certo dia, ao atravessar um rio, Cuidado viu um pedaço de barro. Logo teve uma idéia inspirada. Tomou um pouco do barro e começou a dar-lhe forma. Enquanto contemplava o que havia feito, apareceu Júpiter. Cuidado pediu-lhe que soprasse espírito nele. O que Júpiter fez de bom grado. Quando, porém, Cuidado quis dar um nome à criatura que havia moldado, Júpiter o
Rev Esc Enferm USP 2004; 38(1): 21-7. 
proibiu. Exigiu que fosse imposto o seu nome.

Enquanto Júpiter e o Cuidado discutiam, surgiu, de repente, a Terra. Quis também ela conferir o seu nome à criatura, pois fora feita de barro, material do corpo da Terra. Originou-se então uma discussão generalizada.

De comum acordo pediram a Saturno que funcionasse como árbitro. Este tomou a seguinte decisão que pareceu justa:

Você, Júpiter, deu-lhe o espírito, receberá, pois, de volta este espírito por ocasião da morte da criatura.

Você, Terra, deu-Ihe o corpo; receberá, portanto, também de volta o seu corpo quando essa criatura morrer.

Mas como você, Cuidado, foi quem, por primeiro, moldou a criatura, ficará sob seus cuidados enquanto viver.

E uma vez que entre vocês há acalorada discussão acerca do nome, decido eu: esta criatura será chamada Homem ${ }^{(\mathrm{a})}$, isto é, feita de Húmus, que significa terra fértil. (grifo do autor)

O mito do cuidado carrega um entendimento de como cuidar é central para o ser humano e sua vida. Apresenta uma imagem alegórica da humanidade na qual a característica mais notável de sua origem, vivência e finalidade é o cuidado. Provê, assim, uma genealogia do cuidar, iluminando o repensar do seu valor e de seu sentido para a vida. Oferece uma imagem diferente da sociedade, com diferentes implicações para a ética em geral, para a bioética em particular e, especialmente, para a interface destas com a enfermagem.

Søren Kierkegaard, ainda que de forma incipiente, é o primeiro filósofo a fazer uso da noção de cuidado ou preocupação. Introduz as noções de preocupação, interesse e cuidado para contrapor o que considera a excessiva objetividade da filosofia e da teologia formuladas no começo do século XIX. Para recobrar o sentido e o significado da existência humana individual que, segundo o filósofo, as categorias universais e abstratas da filosofia moderna obliteram, chama a atenção para a ausência da preocupação ou do cuidado no tipo de reflexão filosófica que esses sistemas utilizam ${ }^{(1)}$.

Distingue a reflexão desinteressada e a consciência. A primeira é simplesmente um processo de classificar coisas em comparação com outras, não tem nenhuma preocupação ou interesse com quem conhece ou com o que acontece com a pessoa como resultado deste conhecimento adquirido. A consciência está inerentemente preocupada com quem conhece e com os conflitos que podem surgir a partir do que é conhecido na reflexão, trazendo os elementos objetivos desta para um real relacionamento com o sujeito do conhecimento através do cuidado e da preocupação. Uma relação pessoal com a verdade é a base da teoria do conhecimento de Kierkegaard ${ }^{(1)}$.

Este filósofo também recorre à noção de preocupação para expressar a natureza do ser humano e suas escolhas morais. O indivíduo dá forma ou direção a sua vida e expressa o que the próprio exercitando sua livre escolha e compromisso. Para responder a pergunta fundamental da ética sobre como se deve viver, o raciocínio objetivo desempenha papel importante, mas um argumento ético somente é válido na medida em que explicita uma busca preocupada e individual pelo significado. Assim, a ética começa com o indivíduo, que, sendo obrigado a agir, toma sobre si o interesse e a preocupação decorrentes da responsabilidade com ele próprio. Sem o cuidado ou a preocupação, a ação não seria possível, pois estes elementos constituem o ímpeto para a ação moral resoluta do indivíduo capaz de refletir e agir com propósito ${ }^{(1)}$.

Na filosofia de Martin Heidegger, um dos mais originais e influentes filósofos do século XX, o cuidado não é apenas um conceito entre os demais, mas seu eixo central, o que o faz ser considerado como o filósofo do cuidado por excelência. O desenvolvimento de sua noção de cuidado deriva do tradicional mito de origem greco-latina do cuidado, cuja narrativa é citada literalmente para justificar seu pensamento basilar de que o ser humano leva a marca do cuidado. Os ensinamentos de Kierkegaard acerca da preocupação e do cuidado também exercem uma forte influência conceitual no pensamento heideggeriano, mas há uma diferença essencial. Enquanto o primeiro vê o cuidado de maneira individualizada, subjetiva e psicológica, o último o assume em um nível abstrato e ontológico para descrever a estrutura básica do ser humano ${ }^{(1-2)}$.

O cuidado tem, para Heidegger, o duplo sentido de angústia e solicitude, que representam duas possibilidades fundamentais e conflitantes. O "cuidado angústia" (sorge) retrata a luta de cada um pela sobrevivência e
A redescoberta da ética do cuidado:

o foco e a ênfase nas relações 
por galgar uma posição favorável entre os demais seres humanos. $\mathrm{O}$ "cuidado solicitude" (fürgsorge) significa voltar-se para, acalentar, interessar-se pela Terra e pela humanidade. No mundo cotidiano é inevitável esta divergente ambigüidade do cuidado. Aceitála como própria do ser humano favorece o entendimento de que o cuidado como angústia impulsiona a luta pela subsistência, enquanto compreendê-lo como solicitude permite revelar as plenas potencialidades de cada ser humano ${ }^{(1)}$.

Rollo May, um dos pioneiros da escola da psicologia humanística, numa tentativa de tornar Heidegger mais acessível para a área da saúde, delineia as implicações psicológicas e éticas de seus ensinamentos. Em seu livro Love and Will, escrito em 1969, argumenta que os seres humanos experimentam um mal estar geral e uma despersonalização que resultam em cinismo e apatia. O cuidado, entendido como um estado no qual algo tem importância, conforma o antídoto para a apatia, constituindo seu contrário, porque é a identificação de alguém com a dor ou a felicidade do outro. Argumenta que o cuidado deve ser a raiz da ética, visto que a boa vida vem do que tem importância, do que merece cuidado. A ética tem sua base psicológica na capacidade do ser humano transcender a situação concreta do desejo orientado a si próprio para viver e tomar decisões voltadas ao bem estar das pessoas e dos grupos, dos quais a sua própria satisfação depende intimamente ${ }^{(1)}$.

Erick Erikson, também influenciado, em parte, pela filosofia heideggeriana elabora uma abrangente justificativa de base psicológica para o cuidado. A partir de casos e histórias de vida, propõe uma teoria humanística do desenvolvimento psicológico na qual o cuidado tem papel central. Defende que o ciclo da vida humana tem oito estágios, cada um caracterizado por uma crise desenvolvente ou um ponto decisivo, um momento crítico. Da resolução desta crise emerge uma força psicológica específica, uma virtude ${ }^{(1)}$.

Na sétima fase, a da maioridade, a crise desenvolvente leva ao confrontamento da capacidade gerativa e da absorção em si próprio e a estagnação. A capacidade gerativa configura a preocupação em estabelecer e guiar a próxima geração, propiciando procriação, produtividade e criatividade, já a estagnação manifesta-se na regressão para uma necessidade obsessiva de intimidade. A virtude ou a força básica que emerge desta crise é o cuidado. Desta maneira, o cuidado adulto abarca a tarefa gerativa de cultivar a próxima geração, de preocupar-se concretamente com o que é gerado por amor, necessidade ou acidente ${ }^{(1)}$.

Para este autor, a ética do cuidado envolve a batalha entre a disponibilidade e a indisponibilidade para incluir as pessoas ou os grupos na capacidade gerativa. No primeiro caso, manifesta-se uma força de simpatia que é a virtude do cuidado e no segundo uma inclinação de antipatia, uma tendência à rejeição. Pelo fato do cuidado ser seletivo, é sempre inevitável algum tipo de rejeição. A ética, o direito e o discernimento devem definir a extensão permissível desta rejeição inerente a qualquer grupo. Com o propósito de reduzi-la, a religião e as ideologias devem continuar a defender a universalização do cuidado ${ }^{(1)}$.

Em 1971, o filósofo norte americano Mílton Mayeroff propõe em seu livro, On Caring, uma explanação detalhada das experiências de cuidar e ser cuidado. Apesar de partir dos principais temas discutidos sob a égide da noção de cuidado ao longo da história, imprime-lhe uma visão personalista. Cuidar do outro é ajudá-lo a crescer numa relação mútua, não importando se o outro é uma pessoa, uma idéia, um ideal, uma obra de arte ou uma comunidade. Cuidar é basicamente um processo e não uma série de serviços orientados à consecução de determinados objetivos. O cuidado favorece a devoção, a confiança, a paciência, a humildade, a honestidade, o conhecimento do outro, a esperança e a coragem ${ }^{(1)}$.

Assim, os valores morais são vistos como inerentes ao processo de cuidar e crescer. As responsabilidades e as obrigações relacionadas ao cuidado surgem graças aos recursos internos próprios do caráter e aos compromissos derivados das relações e não devido às regras externas. Quando alguém é alvo de cuidado, cresce de forma a tornar-se mais autodeterminado e a escolher seus valores e ideais com base em sua própria experiência, ao invés de simplesmente conformálos aos predominantes ${ }^{(1)}$.

Alguns outros paradigmas éticos contribuem com discernimentos úteis no desenvolvimento de uma noção da ética do cuidado. A ética da simpatia, desenvolvida por diversos filósofos do fim do século XVII e começo 
do XVIII, como Joseph Butler, David Hume, Adam Smith, Artur Schopenhauer e Max Scheler, representa um deles. Vindo da palavra grega sympatheia, simpatia quer dizer "sentir com", refere-se a um sentimento de preocupação pelo bem estar do outro. Alguns dos autores que contribuem para a conformação de uma idéia de cuidado incluem a simpatia, a empatia ou a compaixão como elementos do cuidado ${ }^{(1)}$.

Outro exemplo concerne às teorias relativas à atenção, à consideração ou ao respeito que têm sido um dos significados de cuidado e permanece como um dos seus elementos até hoje. Cuidar de alguém é prestar-lhe atenção solícita e ter uma disposição de afetividade. Simone Weil, filósofa francesa que viveu de 1909 a 1943, afirmava que a atenção é um esforço que consiste em suspender o próprio pensamento, deixando-o neutro, vazio e pronto para receber o outro, como ele é, em toda sua verdade. Para a resolução de um problema de ordem filosófica, incluindo os éticos, requer-se contemplação cuidadosa, determinada, incansável que o compreenda em toda sua insolubilidade. Desta postura, decorrem a iluminação e a solução do problema, pois se reconhecem deveres antes não percebidos ${ }^{(1)}$.

\section{A ÉTICA DO CUIDADO NA ABORDAGEM DE CAROL GILLIGAN}

Em sua obra considerada como um marco indelével da noção contemporânea de cuidado, Carol Gilligan contrasta a orientação moral primária de meninos e homens com a de meninas e mulheres, assinalando que há tendências de empregar estratégias diferentes de raciocínio e de aplicar temas e conceitos morais distintos na formulação e resolução de problemas éticos. Em seu livro são mencionados três estudos ${ }^{(a)}$ que refletem a hipótese central da autora:

o modo como as pessoas falam de suas vidas é significativo; a linguagem que utilizam e as conexões que fazem revelam o mundo que elas vêem e no qual atuam ${ }^{(3)}$.

Seu objetivo é ampliar a compreensão do desenvolvimento humano, integrando na elaboração de sua teoria o grupo usualmente excluído, com vistas a chamar a atenção para o que falta nos enfoques correntes.

A autora busca registrar os diferentes modos de pensar sobre os relacionamentos e sua

associação com as vozes masculinas e femininas nos dados das pesquisas, nos textos psicológicos e literários. A disparidade entre as experiências dos homens e das mulheres, geralmente, é denotada como um problema de desenvolvimento moral destas. Contrapondo isto, a autora defende que o fato das mulheres não se ajustarem aos modelos existentes pode apontar para problemas de representação, de limites da concepção da condição humana ou de omissão de certos aspectos e verdades sobre a vida. Salienta, no entanto, que estas diferenças têm mais a ver com temas do que propriamente com o gênero:

\begin{abstract}
A voz diferente que eu defino caracteriza-se não pelo gênero, mas pelo tema. Sua associação com as mulheres é uma observação empírica, e é, sobretudo, através das vozes das mulheres que eu traço o seu desenvolvimento. Mas essa associação não é absoluta, e os contrastes entre as vozes masculinas e femininas são apresentados aqui para aclarar uma distinção entre dois modos de pensar e focalizar um problema de interpretação mais do que representar uma generalização sobre ambos os sexos. Ao traçar o desenvolvimento, indico uma interação dessas vozes dentro de cada sexo e sugiro que a sua convergência assinala épocas de crise e mudança ${ }^{(3)}$.
\end{abstract}

O imperativo moral para as mulheres configura-se na obrigação de cuidar, já para os homens, aparece como o dever de respeitar as pessoas protegendo-as de qualquer interferência em sua autonomia ou nos direitos à vida e à auto-realização. A esta perspectiva que define os problemas éticos com base em valores hierárquicos e nas disputas impes-soais de direitos Gilligan chama "ética da justiça", contrapondo-a à "ética do cuidado", prevalente na visão feminina. A integração das dimensões dos direitos e da responsabilidade, devido a sua complementaridade, proporciona para as mulheres o entendimento da lógica psicológica dos relacionamentos, moderando o potencial destrutivo de uma ética autocrítica decorrente da compreensão de que todas as pessoas necessitam de cuidados e, para os homens, corrige a indiferença potencial de uma ética de não-interferência, chamando a atenção para as conseqüências das escolhas ${ }^{(3-5)}$.

Gilligan não cogita sobre as origens das diferenças constatadas e tampouco sua variação histórica, entretanto reconhece que surgem em um contexto social no qual fatores
A redescoberta da ética do cuidado: o foco e a ênfase nas relações

\footnotetext{
(a)Os três estudos mencionados integram um projeto de pesquisa sobre julgamento moral do qual a autora participa. O primeiro envolve 25 estudantes universitários acompanhados a partir do $2^{\circ}$ ano da faculdade até 5 anos após a graduação e investiga o desenvolvimento de identidade moral nos primeiros anos da vida adulta, relacionando a visão do eu e o pensamento sobre moralidade com experiências de conflito moral e a tomada de decisão na vida. A segunda pesquisa envolve decisões sobre aborto de 29 mulheres entre 15 e 33 anos de idade, de diferentes etnias, classes sociais, estado civil e número de filhos e considera o nexo entre experiência e pensamento e $o$ papel do conflito no desenvolvimento. $O$ último estudo abrange uma amostra de 144 homens e mulheres igualados por faixa etária, inteligência, escolaridade, ocupação e classe social em nove momentos do curso de vida e versa sobre concepções do eu e moralidade, experiências e escoIhas em situações de conflitos éticos e julgamento em dilemas morais hipotéticos.
}

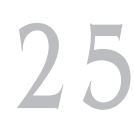

Rev Esc Enferm USP 2004; 38(1):21-7 
como poder e posição social se combinam com a biologia reprodutiva para modelar a experiência de homens e mulheres e as relações entre ambos, como pode ser notado pelo seu entendimento de voz:

Quando as pessoas perguntam-me o significado de voz e eu penso mais refletidamente sobre a questão, digo que por voz eu entendo algo semelhante ao que as pessoas expressam quando falam do âmago de si mesmas. Voz é natural e, também, cultural. É composta de respiração, som, palavras, ritmo e linguagem. Voz é um poderoso instrumento psicológico e um canal que conecta os mundos interno e externo. Falar e ouvir são uma forma de respiração psíquica. Esta troca relacional contínua entre as pessoas é mediada através da linguagem, cultura, diversidade e pluralidade. Por estas razões, voz é uma nova chave para a compreensão da ordem psicológica, social e cultural, um teste para os relacionamentos e uma medida da saúde psicológica( ${ }^{(6)}$.

Constituem elementos chave para a compreensão da ética do cuidado na visão de Carol Gilligan $^{(3)}$ : a consciência da conexão entre as pessoas ensejando o reconhecimento da responsabilidade de uns pelos outros; o entendimento de moralidade como conseqüência da consideração deste relacionamento; a convicção de que a comunicação é o modo de solucionar conflitos.

A centralidade da solução não-violenta de conflitos e da noção de cuidado leva a que se veja as pessoas envolvidas em um conflito ético não como adversários numa pendência de direitos, mas partícipes interdependentes de uma rede de relacionamentos cuja continuidade resulta essencial para a manutenção da vida de todos. Assim, a solução do estado conflituoso consiste em ativar esta rede de relações pela comunicação cooperativa e não competitiva, visando a inclusão de todos mediante o fortalecimento em vez do rompimento das conexões. Os conflitos éticos são problemas que envolvem as relações humanas e ao traçar uma ética do cuidado a autora explora os fundamentos psicológicos dos relacionamentos não violentos. A violência é destrutiva para todos e somente o cuidado torna possível robustecer o eu e os outros. O julgamento moral não pode ter por base regras, mas deve ser nutrido por uma vida vivida de forma suficientemente intensa para criar simpatia por tudo que é humano ${ }^{(3,6)}$.

\section{A ÉTICA DO CUIDADO NA ABORDAGEM DE NEL NODDINGS}

Partindo das idéias de Gilligan e Mayeroff, Nel Noddings, em seu livro Caring: a feminine approach to ethics and moral education editado em 1984, defende que os seres humanos querem cuidar e ser cuidados e que, portanto, há um "cuidado natural" acessível a toda humanidade. Certos sentimentos, atitudes e memórias são universais, embora a resultante do raciocínio ético que os toma por base pode não ser universalizável ${ }^{(7)}$.

A capacidade de agir eticamente é entendida pela autora como uma "virtude ativa" que requer dois sentimentos: o primeiro é o sentimento natural de cuidado e o segundo ocorre em resposta à lembrança do primeiro, pois cada pessoa traz consigo uma memória dos momentos nos quais cuidou ou foi cuidada podendo acessá-la e, caso assim o deseje, por ela guiar sua conduta. Há momentos em que cuidar apresenta-se como algo completamente natural, não impondo conflitos éticos, porque o "querer" e o "dever" coincidem. A questão gira em torno à exigibilidade do cuidado. $\mathrm{Na}$ opinião de Noddings ${ }^{(7)}$, certamente, não pode haver uma exigência acerca do impulso natural que brota como um sentimento, uma voz interna que diz "eu devo fazer algo" em resposta às necessidades do outro. A autora defende que, a menos que haja alguma patologia, este impulso surge naturalmente, mesmo que de forma ocasional. Não se pode exigir que alguém tenha este impulso, mas os que nunca o manifestam são, geralmente, repudiados.

Mas, como lembra a autora, não se deve descartar a hipótese de que ao sentir o impulso natural inicial a pessoa o rejeite, passando do "eu devo fazer algo" para "algo deve ser feito", excluindo-se, desta forma, do rol de possíveis agentes através dos quais a ação poderia ser realizada. Cuidar requer que a pessoa responda ao impulso inicial com um ato de compromisso, o que configura o segundo sentimento, genuinamente ético e que brota da avaliação dos relacionamentos de cuidado como algo bom, melhor do que qualquer outra forma de relação. A pessoa que cuida reconhece que sua resposta pode fortalecer ou diminuir seu ideal ético, pode afetá-la como "alguém que cuida". Assim, a fonte de obrigação para o segundo sentimento reside no valor atribuído às relações de cuidado como resultante do cuidar e do ser cuidado real e da 
reflexão sobre o quanto estas situações concretas de cuidado são boas. Tudo depende, em última instância, da vontade e da decisão individual de ser bom e de permanecer num relacionamento de cuidado com os outros ${ }^{(7)}$.

\section{A ÉTICA DO CUIDADO: FEMININA OU FEMINISTA?}

Os esforços para caracterizar uma ética do cuidado chamando a atenção para as diferenças de raciocínio ético entre homens e mulheres ocorrem em meio a importantes avanços da ética feminista. Cabe, entretanto, distinguir a ética do cuidado, especialmente as descritas por Carol Gilligan e Nel Noddings, que têm sido chamadas de "ética feminina" ou "ética do feminino" e a "ética feminista". O interesse primário das éticas femininas está em descrever as experiências morais e as intuições das mulheres, apontando como as abordagens éticas tradicionais têm negligenciado a inclusão desta perspectiva. Por outro lado, as éticas feministas têm como propósito principal repudiar e por fim à opressão sofrida pelas mulheres e outros grupos historicamente oprimidos, estando, portanto, muito mais preocupadas do que as primeiras em provocar transformações político-sociais ${ }^{(4)}$.

Um temor é que as éticas femininas acabem por minar, ainda que sem intenção, o feminismo, pois as qualidades que atribuem aos homens e às mulheres foram construídas no contexto de uma cultura sexista. Enfatizar o cuidado como virtude feminina pode servir para manter as mulheres no lado mais vulnerável da relação de gêneros. Apesar destas diferenças e temores assinalados, as duas abordagens da ética são congruentes em muitos aspectos. O estudo detalhado da vida e do raciocínio ético das mulheres feito pelas éticas femininas pode contribuir, substancialmente, para desmantelar hábitos de pensamento e práticas favorecedores da opressão ao gênero feminino. Ambas compartilham do objetivo de incluir a voz e a perspectivas das mulheres nos vários campos dos estudos acadêmicos.

\section{CONSIDERAÇÕES FINAIS}

Parece claro que no desenvolvimento da noção de cuidado têm concorrido, ao longo da história, várias abordagens, como a mitológica, a religiosa, a filosófica, a psicológica e a teológica, que acabam por influir orientações éticas e comportamentos morais. Disto decorrem distintas estruturas explicativas para a ética do cuidado, incluindo sua compreensão como ética evolucionária, ética da virtude, ética do desenvolvimento, ética da responsabilidade e ética do dever. Os aspectos históricos revelam que não há uma idéia única de cuidado, mas um conjunto de noções de cuidado que se unem por alguns sentimentos básicos, por algumas narrativas formativas, cuja influência perdura através dos tempos e por diversos temas recorrentes. A questão chave, no entanto, está nas motivações do descaso à noção de cuidado e sua incipiente influência na ética. É provável que a resposta a esta questão esteja no fato do cuidado apresentar-se como uma cativante emoção ou idéia que tem confrontado e desafiado os sistemas de pensamento racionalistas, abstratos, impessoais e detentores de abrangente ascendência social, ética, política e religiosa, apoiando sua visão da condição humana na capacidade das pessoas importarem-se com os outros, com as coisas, com a comunidade, com uma trajetória de vida ou consigo próprias. Neste sentido, a ética do cuidado tem desempenhado um papel de contra cultura.

\section{REFERÊNCIAS}

(1) Reich WT. History of the notion of care. In: Reich WT, editor. Bioethics encyclopedia. $2^{\text {nd }}$ ed. [CD ROM]. New York: Mac Millan Library; 1995.

(2)Boff L. Saber cuidar: ética do humano, compaixão pela terra. Petrópolis: Vozes; 1999.

(3)Gilligan C. Uma voz diferente: psicologia da diferença entre homens e mulheres da infância à idade adulta. Rio de Janeiro: Rosa dos Tempos; 1982.

(4) Reich WT, organizer. Contemporary ethics of care. In: Reich WT, editor. Bioethics encyclopedia. $2^{\text {nd }}$ ed. [CD ROM]. New York: Mac Millan Library; 1995.
A redescoberta da ética do cuidado:

o foco e a ênfase nas relações
(5) Beauchamp TL, Childress JF. Principios de ética biomédica. $4^{\mathrm{a}} \mathrm{ed}$. Barcelona: Masson; 1999.

(6) Gilligan C. In a different voice: psychological theory and women's development. Massachusetts: Harvard University Press; 1993.

(7) Noddings N. Caring: a feminine approach to ethics and moral education. Berkeley: University of California Press; 1984. 